\title{
USM3D Simulations of Saturn V Plume Induced Flow Separation
}

\author{
Karen Deere ${ }^{1}$, Alaa Elmiligui ${ }^{2}$, K.S. Abdol-Hamid ${ }^{3}$ \\ NASA Langley Research Center, Hampton, VA, 23681
}

The NASA Constellation Program included the Ares $\mathrm{V}$ heavy lift cargo vehicle. During the design stage, engineers questioned if the Plume Induced Flow Separation (PIFS) that occurred along Saturn V rocket during moon missions at some flight conditions, would also plague the newly proposed rocket. Computational fluid dynamics (CFD) was offered as a tool for initiating the investigation of PIFS along the Ares $\mathrm{V}$ rocket. However, CFD best practice guidelines were not available for such an investigation. In an effort to establish a CFD process and define guidelines for Ares $V$ powered simulations, the Saturn V vehicle was used because PIFS flight data existed. The ideal gas, computational flow solver USM3D was evaluated for its viability in computing PIFS along the Saturn V vehicle with F-1 engines firing. Solutions were computed at supersonic freestream conditions, zero degree angle of attack, zero degree sideslip, and at flight Reynolds numbers. The effects of solution sensitivity to grid refinement, turbulence models, and the engine boundary conditions on the predicted PIFS distance along the Saturn V were discussed and compared to flight data from the Apollo 11 mission AS-506.

CECO
CFL
$\mathrm{C}_{\mathrm{j}}$
$\mathrm{C}_{\mathrm{Nmax}}$
$\mathrm{C}_{\mathrm{ave}}$
$\mathrm{C}_{\mathrm{AF}}$
$\mathrm{C}_{\mathrm{N}}$
$\mathrm{C}_{\mathrm{Y}}$
$\mathrm{C}_{1}$
$\mathrm{C}_{\mathrm{m}}$
$\mathrm{C}_{\mathrm{n}}$
$\mathrm{D}$
delta 1
$\log (\mathrm{r} / \mathrm{r} 0)$
$\log ($ tnu/tnu 0$)$
$\mathrm{L}$
$\mathrm{L}_{\mathrm{USM} 3 \mathrm{D}}$
$\mathrm{M}$
$\mathrm{p}_{\infty}$
$\mathrm{q}$
$\mathrm{R}$
$\mathrm{Re} \mathrm{D}_{\mathrm{D}}$
$\mathrm{ReUe}$
$\mathrm{S}_{\mathrm{ref}}$
$\mathrm{T}_{\infty}$
$\mathrm{u}$
$\mathrm{V}_{\infty}$
$\mathrm{x}, \mathrm{y}, \mathrm{z}$
$\mathrm{X}_{\mathrm{mrc}}$

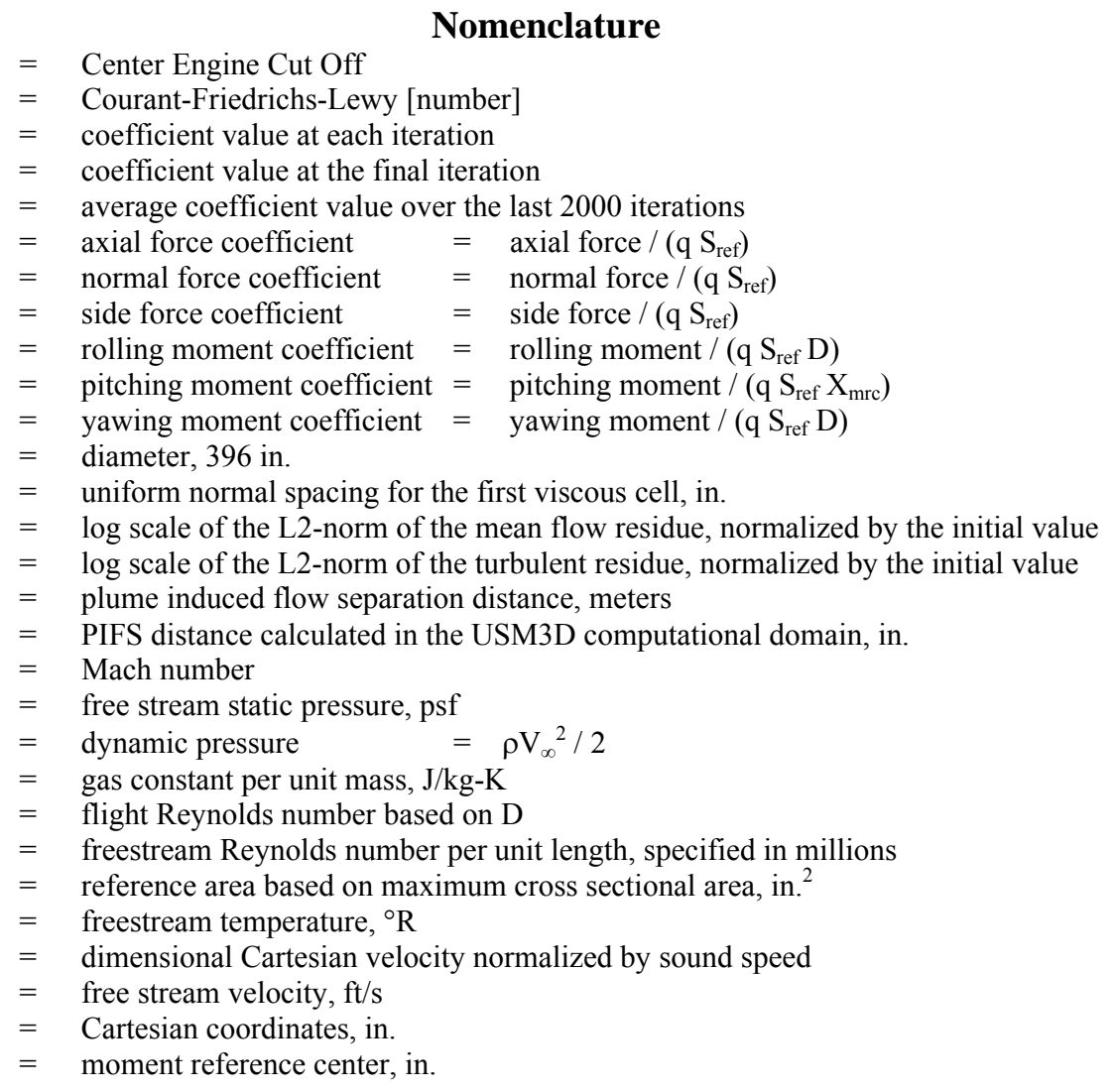

\footnotetext{
1 Aerospace Engineer, Research Directorate, MS 499, AIAA Senior Member

2 Aerospace Engineer, Research Directorate, MS 499, AIAA Member

3 Aerospace Engineer, Research Directorate, MS 499, AIAA Associate Fellow
} 


$\begin{array}{lll}\mathrm{X}_{\mathrm{FLT} \_ \text {REF }} & = & \text { flight reference location for measuring PIFS, } \mathrm{x}=0 \\ \mathrm{y}^{+} & = & \text {nondimensional height of the first cell off the surface in the boundary layer } \\ \alpha & = & \text { body axis angle of attack, deg } \\ \beta & = & \text { body axis sideslip angle, deg } \\ \rho & = & \text { density, slugs } / \mathrm{ft}^{3} \\ \%_{\mathrm{OR}} & = & \text { percent over range, convergence Eq. }(1)\end{array}$

\section{Introduction}

The NASA Constellation Program included research on two space access vehicles to replace the Space Shuttle; the Ares I Crew Launch Vehicle and the Ares V Cargo Launch Vehicle. ${ }^{1-2}$ The Ares I was envisioned to launch astronauts and the Ares V to launch equipment into low earth orbit (LEO), to the Moon, and eventually onto Mars. The concept image of the Ares V two-stage launch system is shown in figure $1 .^{3}$ The core stage includes two 5.5segmented reusable solid rocket boosters and a central booster with five RS-68 engines fueled with liquid oxygen and liquid hydrogen. Above the core stage is the interstage, the loiter skirt, and the earth departure stage (EDS). The EDS is powered with an expendable liquid oxygen and liquid hydrogen J-2X engine. Finally, the payload shroud protects the cargo payload, which happens to be the Altair Lunar Lander shown in figure 1.

At this early stage of planning and designing the Ares V launch system, computational analysis can be extremely helpful and cost effective for evaluating the vehicle's aerodynamic performance for various design changes. During one of the Ares V design cycles, engineers familiar with the Saturn V rocket flight experiment, questioned the possibility of plume induced flow separation (PIFS) along Ares V. Computational fluid dynamics (CFD) was offered as a tool for initiating the investigation of PIFS along the Ares V rocket. However, CFD best practice guidelines were not available for such an investigation. In an effort to establish a CFD process and define guidelines for Ares V powered simulations, the Saturn V vehicle was used because PIFS flight data exists. ${ }^{4-6}$ Additionally, conditions in which PIFS may be an issue for Ares V could occur after the separation of the reusable solid rocket boosters from the core stack, in which case the Ares V becomes more geometrically similar to the Saturn V.

The Saturn V rocket launched NASA astronauts in the Apollo and Skylab programs. ${ }^{7,8}$ A sketch of the threestage Saturn V rocket is shown in figure 2. The Saturn V first stage is powered with five Rocketdyne F-1 engines, the second stage is powered with five Rocketdyne J-2 engines, and the third stage has one Rocketdyne J-2 engine. CFD analysis of the full stack Saturn V rocket with the availability of flight data could help determine the viability of the numerical method for predicting PIFS phenomena. In particular, the authors were focused on establishing viability of and guidelines for USM3D to predict PIFS. The USM3D CFD code is a tetrahedral cell-centered, finite volume Euler and Navier-Stokes (N-S) method. A similar study of the Saturn V PIFS was completed with the structured-grid, OVERFLOW CFD code. ${ }^{9}$

For the current study, the USM3D CFD code was used to calculate supersonic freestream flow around the Saturn $\mathrm{V}$ rocket at Mach numbers from $\mathrm{M}=1.5$ to $\mathrm{M}=6.5$. For $\mathrm{M}=1.5$ to $\mathrm{M}=4.4$, all five $\mathrm{F}-1$ engines were firing. For the $\mathrm{M}=6.5$ case, the center engine was not firing $(\mathrm{CECO}=$ center engine cut off $)$. Although USM3D is an ideal gas flow solver, the code has been successfully used up to Mach 7 with accurate comparisons of integrated force and moment coefficients, surface pressures, and component loads of the Hyper-X Launch Vehicle. ${ }^{10}$ This investigation of PIFS along the Saturn V rocket included (1) evaluating the impacts of engine boundary condition on PIFS distance (L), (2) a grid density study on prediction of L, and (3) variations in L due to turbulence model selection. After establishing the viability of USM3D for PIFS calculations, the process and lessons learned are documented for future applications. The best practices established for ascent aerodynamics of the Ares I configuration ${ }^{11}$ and the Ares $\mathrm{V}$ configuration ${ }^{12}$ were used as guidelines for this work.

\section{Saturn V Flight Data}

The Saturn V flight trajectory and PIFS flight data for the Apollo 11 mission was extracted from reference 7 and shown in figure 3. The four CFD cases chosen for this study are highlighted with a red $\mathrm{x}$ in figure 3 and the flight conditions are summarized in table 1. The Saturn V vehicle used in the Apollo 11 mission was denoted as AS-506. The reference location for calculating the PIFS distance is shown in figure 4. The flight reference point ( $\mathrm{X}_{\mathrm{FLT}}$ REF $)$ was located at the $\mathrm{x}=0$ location in the computational domain. Separation along the vehicle occurs in the negative $\mathrm{x}$ direction (fig. 4). Therefore, the PIFS length was calculated with equation 1. The Airborne Lightweight Optical Tracking System (ALOTS) was used to observe the flow separation location on the Saturn V AS-506 vehicle in flight. The uncertainty of flight PIFS data was estimated at least \pm 10 percent.

$$
L_{U S M 3 D}=0-x
$$




\section{Methods Description}

The NASA Tetrahedral Unstructured Software System (TetrUSS) used for this computational analysis was developed at NASA Langley Research Center (LaRC). ${ }^{13}$ TetrUSS includes a model/surface grid preparation tool (GridTool), field grid generation software (VGRID, POSTGRID) and a computational flow solver (USM3D). The USM3D flow solver has internal software to calculate forces and moments. Additionally, the NASA LaRCdeveloped code USMC6 was used for analyzing the solutions. ${ }^{14}$

\section{A. Grid Generation}

The NASA Marshall Space Flight Center (MSFC) delivered the geometry definition for the Saturn V AS-506 in an IGES format. The geometry file included only large-scale geometric features. The length and diameter of each section, the engine fairings, and the distance between each engine were all maintained, while the fins and smallscale geometric features were removed from the numerical model. The OVERFLOW team ${ }^{10}$ used the IGES file to prepare and deliver a surface definition in a PLOT3D unformatted, double precision file format for use by the USM3D team. The PLOT3D surface definition was then prepared in GridTool ${ }^{15}$ by creating surface patches on the configuration and by placing sources throughout the domain to accurately capture configuration characteristics. The output from GridTool was used to automatically generate the computational domain with the VGRID unstructured grid generation software. VGRID uses an Advancing Layers Method to generate thin layers of unstructured tetrahedral cells in the viscous boundary layer, ${ }^{16}$ and an Advancing Front Method to populate the volume mesh in an orderly fashion. ${ }^{17}$ Finally, POSTGRID was used to close the grid by filling in any gaps that remain from VGRID. POSTGRID is automated to carefully remove a few cells surrounding any gaps in the grid and precisely fill the cavity with the required tetrahedral cells.

Some guidelines for grid generation included the requirement for surface cell size to be small enough to resolve features and curvature and for proper boundary layer spacing to ensure $\mathrm{y}^{+}$remains less than or equal to 1 for the selected free stream Mach and Reynolds numbers. In many cases the latter requirement required more than one grid to be used over a range of Mach and Reynolds numbers.

The full domain mesh is specified in inches with the following boundaries: $-12000<\mathrm{x}<15000,-12000<\mathrm{y}<12000$, and $-12000<\mathrm{z}<12000$. The boundary layer parameter definitions were specified in Gridtool as NLayer=100, Rate $1=0.16$ and Rate $2=0.04$. The NLayer parameter sets the maximum number of viscous layers, Rate 1 is radial grid growth rate and Rate2 is radial grid growth acceleration rate. The VGRID software used these values to create the desired spacing of cells within the boundary layer. Two meshes were made to satisfy practical $\mathrm{y}^{+}$values over a range of Mach and Reynolds numbers. The parameter deltal sets the first cell height off the solid surface and the values are shown in table 2 with the resulting $\mathrm{y}^{+}$values for given Mach number and Reynolds number combinations. Table 3 shows the cell count for the various meshes used to determine the mesh density impacts on PIFS distance.

Figure 5 shows the surface mesh on the crew module, service module and around the F-1 engines. The geometry shown in figure 5 was rotated around the $\mathrm{x}$ axis by 135 degrees in comparison with the view in figure 4 , to show the center engine. The apex of the configuration was located at $x=-4241.38$ inches, $y=0$, and $z=0$ and the base of the first stage was located at $x=-112$ inches. The trailing edge of the engine fairings were located at $x=-45$ inches and the trailing edge of the nozzles were located at $x=116.6$ inches. The internal geometry of the F-1 nozzles was not modeled in the computational domain, but was simulated with an engine boundary condition located 2 inches upstream of the actual exit plane, as shown in figure 6 . The engine boundary condition planes are located at $\mathrm{x}=114.6$ inches.

\section{B. Computational Flow Solver}

The TetrUSS flow solver USM3D is a tetrahedral cell-centered, finite volume Euler and Navier-Stokes (N-S) method. The USM3D flow solver has a variety of options for solving the flow equations and two turbulence models for closure of the N-S equations. ${ }^{18,19}$ Following the guidelines for ascent aerodynamics of the Ares I configurations, ${ }^{11}$ fully turbulent calculations were computed using the recommended Spalart-Allmaras (SA) turbulence model. A script program, written as part of the Ares-I guidelines development, was used to automatically setup input parameters for choosing the proper flux scheme and CFL numbers based on the desired Mach number for each case. For Mach numbers larger than 2.5, the Harten, Lax and van Leer with the contact restoration (HLLC) spatial differencing scheme is used for the inviscid flux discretization and $\mathrm{CFL}_{\max }$ is set to 10 . For Mach numbers less than 2.5, Roe's flux difference splitting scheme is used and $\mathrm{CFL}_{\max }$ is set to 40 . Flux limiters are used within CFD codes to preclude oscillations due to shocks and discontinuities by limiting the values of the spatial derivatives. Typically, a flux limiter is required for supersonic flows and not for subsonic flow computations. At the start of a 
new solution, the USM3D code typically runs with first order spatial accuracy until the residual dropped two orders of magnitude, and then the code automatically switches to second order spatial accuracy.

\section{Coordinate System}

For USM3D, the positive $\mathrm{x}$ axis must be in the freestream flow direction and the $\mathrm{y}$ and $\mathrm{z}$ axes aligned in a right handed coordinate system with the $\mathrm{x}$ axis. Angle of attack is defined in the x-z plane and sideslip angle is defined in the $\mathrm{x}-\mathrm{y}$ plane. For this investigation, sideslip angle and angle of attack are set to zero.

\section{Flow Conditions}

For each free stream flow condition, the user must specify the Mach number, angle of attack, the sideslip angle, and the freestream Reynolds number per unit length in millions (ReUe). The ReUE parameter was calculated with equation 2 . The matrix of flow conditions used in this investigation is shown in table 1.

$$
\operatorname{Re} U E=\left(\frac{\operatorname{Re}_{D}}{D^{*} 10^{6}}\right)
$$

\section{E. Initial and Boundary Conditions}

A no-slip viscous boundary condition $(\mathrm{BC})$ was used on all solid surfaces of the vehicle. A supersonic inflow boundary condition was used at the domain inflow face and an extrapolation boundary condition was used at the downstream outflow face of the domain. A characteristic inflow and outflow boundary condition was used along the far field, lateral faces of the outer domain.

The liquid rocket, F-1 engines were modeled with a truncated nozzle. The convergent-divergent section of the F1 engine nozzles were not modeled, and only the last 2 inches of the divergent section at the nozzle exit were included in the computational domain. There were a few approaches to setting the engine flow conditions along the truncated plane just 2 inches upstream of the nozzle exit plane.

The first approach was denoted as the Average Pressure Average Values (APAV BC). The APAV BC was generated by simply using the average values of the flow quantities (Mach, pressure, temperature) as constant values at every cell across the nozzle exit plane.

The second approach was to use the NASA Langley developed structured CFD code PAB3 $\mathrm{D}^{20}$ to calculate a boundary condition. PAB3D can be used to obtain a frozen chemistry multispecies calculation if the nozzle geometry is known. In using this approach, the thrust, Mach number, mass flow rate, real gas constant (Rgas $=358$ $\mathrm{J} / \mathrm{kg} \mathrm{k})$ and specific heat ratio $(\gamma=1.24)$ at the nozzle exit plane are used to create a modified expansion ratio nozzle. By running PAB3D in the modified expansion ratio nozzle and simulating the main species $\left(34 \% \mathrm{CO}, 16 \% \mathrm{CO}_{2}\right.$, $16 \% \mathrm{H}_{2}$ and $34 \% \mathrm{H}_{2} \mathrm{O}$ ), the code will produce a boundary condition similar to the higher fidelity, $\mathrm{F}-1 \mathrm{BC}$.

The third approach, denoted as F-1 BC, was to obtain the exit flow conditions from a multispecies, multiphase, chemically reacting simulation in the real nozzle geometry. Bud Smith at NASA MSFC completed the real-gas, realnozzle simulation and provided the exit flow conditions in the form of a 2-D velocity, density, and pressure profiles. The exit flow conditions were adjusted from the exit plane and applied to the 2-inch truncated nozzle depth in the USM3D computational domain.

Figure 7 shows the comparison of the exit profiles for various variables from the PAB3D and F-1 engine boundary conditions. The $y$ value represents the radius of the circular nozzle exit plane, with $y=0$ at the centerline and $y=69$ inches at the wall of the nozzle. The Mach number and velocity profiles compare well between the two boundary conditions, with PAB3D BC slightly lower in magnitude than F-1 BC over the range of $\mathrm{y}$. The temperature profiles compare well, except at the wall. The differences at the wall may result from differences in wall boundary condition. The PAB3D BC assumes an adiabatic wall temperature and with no losses the wall temperature should approach total temperature $\left(\approx 7000^{\circ} \mathrm{R}\right)$. The F-1 BC may have a constant wall temperature of $1000^{\circ} \mathrm{R}$. The $\mathrm{PAB} 3 \mathrm{D} \mathrm{BC}$ has higher pressure and density for $\mathrm{y}<50$ inches than the F-1 BC. Identical comparisons were not expected as the F-1 BC is a multi-species calculation inside the true nozzle geometry, while the PAB3D calculation is frozen chemistry multispecies calculation within a modified nozzle. These comparisons indicate that the PAB3D $\mathrm{BC}$ is a reasonable approximation for the $\mathrm{F}-1 \mathrm{BC}$.

\section{F. Convergence}

Two main criteria were used to monitor and determine solution convergence. First, a drop in residual of at least two orders of magnitude was desired. In general, all solution residuals dropped from 4 to 6 orders of magnitude. 
Second, convergence of force and moment coefficients was evaluated with a percent over a range $\left(\%_{\mathrm{OR}}\right)$ value of less than 0.5 percent for each coefficient. The coefficients were averaged over 2000 iterations and the standard deviation and $\%_{\mathrm{OR}}$ were calculated for each coefficient. The $\%_{\mathrm{OR}}$ value was calculated with equation 3 , where $\mathrm{C}_{\mathrm{Nmax}}$ is the value of the coefficient at the last iteration.

Examples of solution history plots are shown in figure 8 for the Saturn V rocket powered USM3D simulations using the SA turbulence model at $\mathrm{M}=6.5, \alpha=0^{\circ}, \beta=0^{\circ}$, and $\mathrm{Re}_{\mathrm{D}}=406,000$. Figure 8(a) shows a typical converged solution with a decreasing residual, except for the spikes caused by manual changes in the input file or when the solver algorithm changed from first to second order. A typical solution history of the force and moment coefficients is shown in figure 8(b). Each coefficient flattens out to a constant value for a converged solution.

Table 4 shows a typical summary of the force and moment calculations for determining convergence. Solutions are deemed converged when the $\% \mathrm{OR}$ values are less than 0.5 . In the situation where the coefficient is approaching zero, the percent over range values may be larger than 0.5 percent because of the near zero average value of the coefficient in the denominator of equation 2. The higher percent over range calculations (when the coefficient average is near zero) can be deceiving and therefore engineering judgment is used to determine convergence and conserve resources. A combination of plots in figure 8 and evaluating the standard deviation of each average coefficient can help guide solution convergence.

$$
\begin{gathered}
\%_{O R}=\frac{C_{N_{\max }}-C_{\left(N_{\max }-999\right)}}{C_{\text {ave }}} \times 100 \% \\
\text { where }: C_{\text {ave }}=\frac{1}{1000} \sum_{j=N_{\max }-999}^{N_{\max }}\left(C_{j}\right)
\end{gathered}
$$

\section{Results}

The main objective of the current work was to assess the viability of the USM3D flow solver for predicting PIFS using ideal gas simulations. If USM3D proved viable for calculating PIFS, the secondary objective was to develop a process or set of guidelines as a starting point for future applications. The approach to achieving the objectives included using the Saturn V rocket, evaluating different boundary conditions for modeling the F-1 engines firing, investigating grid changes, and testing the impacts of various turbulence models on the prediction of $\mathrm{L}$.

The Saturn V rocket was used for this study because some flight test data was available from the Apollo 11 mission. ${ }^{7}$ The Saturn V flight test PIFS data and flow conditions are shown in figure 3. Four cases were selected from figure 3 and are shown in table 5. For the $\mathrm{M}<5$ cases, all five engines are firing. However, for the $M=6.5$ cases, the center engine was cut off (CECO). Therefore, the CFD solutions for $\mathrm{M}<5$ simulated all five engines firing, but the $\mathrm{M}=6.5 \mathrm{CFD}$ solution also simulates $\mathrm{CECO}$.

The flight test uncertainty error for $\mathrm{L}$ was estimated to be at least 10 percent. Ideal gas solutions were computed with USM3D at four Mach numbers with appropriate engine boundary conditions for each Mach number. There are many factors that may affect accurate prediction of plume induced flow separation along a launch vehicle. Implementing an appropriate engine boundary condition, using an adequate mesh resolution, and understanding turbulence model effects are just a few factors affecting PIFS calculations. First, the various engine boundary conditions were investigated. Second, a grid sensitivity study was conducted. Third, results using two turbulence models were examined. Finally, the results were examined to establish guidelines for future applications.

\section{A. Evaluating Engine Boundary Conditions}

To start this work, only the average values of the flow quantities at the F-1 nozzle exit plane were available. Therefore, the first BC option used in this study was Average Pressure Average Values (APAV BC), generated by simply using the average values of the flow quantities (Mach, pressure, temperature) as constant values at every cell across the nozzle exit plane.

The second, higher-fidelity $\mathrm{BC}$ option was the PAB3D BC. This boundary condition was generated with the PAB3D CFD code in an effort to produce variations in the flow quantities across the nozzle radius, instead of constant values at all cells used in the first BC. The PAB3D BC was generated with a modified expansion ratio, 2D nozzle, which produced radial variations of the flow quantities which also matched the given average values at the exit profile. 
The third, highest fidelity $\mathrm{BC}$ option was the $\mathrm{F}-1 \mathrm{BC}$. The $\mathrm{F}-1 \mathrm{BC}$ was generated from a real-gas multispecies and multiphase, chemical reaction simulation in the true F-1 nozzle geometry. The F-1 BC was viewed as the most appropriate $\mathrm{BC}$ for modeling the true conditions in the rocket nozzles.

For all $\mathrm{BC}$ options, the full engine nozzles were not modeled in the computational domain. Figure 6 shows the engine boundary plane, truncated 2 inches into the nozzle from the exit, at which point the engine boundary conditions were applied.

Table 6 shows the PIFS distance, calculated from USM3D solutions on the fine mesh with the SA turbulence model, for the three boundary conditions at the four selected Mach numbers. Flight data and computational data indicated no PIFS for Mach 1.5. At Mach 2.7, flight data PIFS was 3 meters but no flow separation was predicted with USM3D. Flight data indicated large PIFS distances for $\mathrm{M}=4.4$ and $\mathrm{M}=6.5$. USM3D predicted various amounts of PIFS, depending upon which engine $\mathrm{BC}$ was used.

The non-dimensional velocity contours and velocity-based streamtraces show the effect of engine boundary condition on PIFS for solutions computed at $\mathrm{M}=4.4$ and $\mathrm{M}=6.5$ in figures 9 and 10, respectively. The APAV BC under-predicted PIFS distance compared to flight data at both $\mathrm{M}=4.4$ and $\mathrm{M}=6.5$. The fine mesh SA turbulence model solution data, using PAB3D BC, compared reasonably well with the uncertainty band in flight data.

Using the F-1 BC was considered the most appropriate $\mathrm{BC}$ method for the engine conditions because the true $\mathrm{F}-1$ nozzle geometry was used. However, using the SA turbulence model and the fine mesh with the F-1 BC underpredicted PIFS flight data.

\section{B. Grid Resolution Study}

This section will discuss the mesh sensitivity study, beginning with the boundary layer definition and following with the mesh density within the full domain. First, an appropriate boundary layer mesh along solid surfaces can only be generated after considering all of the flow conditions in a test matrix. The flow conditions for the Saturn $\mathrm{V}$ PIFS study spanned too large of a Mach number range and a flight Reynolds number range to use just one mesh for all conditions. To maintain decent convergence and to adequately develop the boundary layer, the nondimensional height of the first cell in the boundary layer was kept within a reasonable range $\left(0.1<\mathrm{y}^{+}<1\right)$. Two meshes, each with a different dimensional first cell heights (delta1), were required to keep $\mathrm{y}^{+}$within a reasonable range for the desired conditions in the test matrix. As shown in table 2, delta1 $=0.002$ inches for the $M=1.5$ and $M=2.7$ cases, and delta1 $=0.08$ inches for the $\mathrm{M}=4.4$ and $\mathrm{M}=6.5$ cases. Second, an adequate mesh density throughout the domain is required to capture the flow features of interest. Since the flight data indicated more PIFS at M $=4.4$ and $\mathrm{M}=6.5$ than $\mathrm{M}<4$, only the $\mathrm{M}>4$ conditions and the mesh with the delta1 $=0.08$ boundary layer definition were used for the mesh sensitivity study. Based on grid generation experience within the Ares I project, the medium mesh (table 3) was considered to be a reasonable size and was chosen as the baseline mesh. Cell count was increased by 59 percent for the fine mesh, and decreased 33 percent for the coarse mesh, relative to the baseline medium mesh. All solutions in the grid resolution study used the PAB3D BC to model the engines firing.

The flight data indicated no PIFS for the $\mathrm{M}=1.5$ case, so this case was excluded from the grid study. Flight data indicated $\mathrm{L}=3$ meters of PIFS for $\mathrm{M}=2.7$, but the medium mesh solution indicated no PIFS. A fine mesh with 71.8 million cells was created with the delta $1=0.002$ boundary layer definition to see if increasing the cell count by 58 percent would capture some flow separation indicated in flight. The $\mathrm{M}=2.7$ case was calculated on the fine mesh but the solution still indicated no PIFS, similar to the medium mesh.

The effect of mesh density on PIFS for $M=4.4$ and $M=6.5$ is shown in figures 11 and 12 , respectively. The non-dimensional velocity contours are shown on the Saturn V surface and on the $y=0$ plane. The velocity-based streamtraces shown in black indicate the line of separation where the vectors in the positive $\mathrm{x}$ and negative $\mathrm{x}$ directions meet. Table 7 shows the effect of mesh density on PIFS distance for $M=4.4$ and $M=6.5$. The separation length for the $\mathrm{M}=4.4$ case, changes 2.9 percent from the coarse to medium mesh and is constant from the medium to fine mesh, indicating that the $\mathrm{M}=4.4$ solution is roughly grid independent on the baseline medium mesh. Furthermore, for initial studies or situations in which resources are limited, the coarse mesh provided a good estimate of PIFS with 33 percent less grid. Smaller grids require less computer processors to run the USM3D code.

After achieving a roughly grid independent solution for the $\mathrm{M}=4.4$ case on the medium mesh, it was unexpected to see larger changes from the medium to fine mesh than the coarse to medium mesh for the $M=6.5$ case. The separation length for the $\mathrm{M}=6.5$ case, changed only 1 percent from the coarse to medium mesh and 3.2 percent from the medium to fine mesh. However, these are small changes in PIFS distance for the substantial change in grid size and increase in computer processors required. A general guideline for the number of processors needed for a particular grid size is shown in equation 4.

$$
\# \text { processors }=\# \text { cells } \div 300,000
$$


Using equation 4, the coarse mesh solutions would require around 89 processors, the medium mesh would require 134 processors and the fine mesh solution would require 213 processors.

\section{Turbulence Model}

The SA turbulence model was the default turbulence model used by the CFD teams within the Ares V program because it was established in the best practices guidelines for power-off ascent aerodynamics in the Ares I program. ${ }^{11}$ However, more advanced turbulence models are typically used for engine and plume calculations where flow separation is expected. ${ }^{18,19}$ Therefore, both the SA and the SST turbulence models were investigated for this study. Details of both models as implemented into USM3D can be found in reference 19.

For the turbulence model study, solutions were computed at $\mathrm{M}=6.5$ using the $\mathrm{F}-1 \mathrm{BC}$ on the coarse and medium meshes. The F-1 BC was used because it was considered the highest fidelity boundary condition of the three options investigated in this study. The computed PIFS distance is shown in table 8 . The flight data PIFS distance for M=6.5 was $\mathrm{L}=33 \pm 3.3 \mathrm{~m}$.

The SA turbulence model with the F-1 BC underpredicted flight PIFS distance by 33 percent. However, the SST turbulence model with the F-1 BC is within 6 to 7 percent of flight data, which is the best correlation of the flight data from any of the combinations of turbulence model and boundary condition in this study. There was less than 1 percent change in PIFS distance between the coarse mesh and medium mesh F-1 BC solutions, indicating again, that the coarse mesh can provide accurate initial predictions of PIFS solutions.

Prior to this study the SA turbulence model was used for non-powered ascent aerodynamics in the Ares Program, but other references indicated a benefit of the SST model for separated flow cases. The pairing of the highest fidelity F-1 BC and the SST turbulence model has provided the best prediction of $\mathrm{L}$ for the $\mathrm{M}=6.5 \mathrm{CECO}$ case. The non-dimensional velocity contours with velocity-based streamtraces are shown in figure 13 for the $\mathrm{M}=6.5$ case using the F-1 BC and the SST turbulence model. There was not sufficient time to conduct further analysis for the solution at $\mathrm{M}=4.4$ with the SST turbulence model and the F-1 BC. This work could be investigated in a future study.

\section{Suggested Process}

As a starting point for calculating PIFS using the USM3D CFD code in the preliminary stages of a launch vehicle, the following guidelines have been established from the current work. First, use a mesh comparable to the coarse mesh in this document. Second, use an appropriate boundary layer definition for given flight Reynolds number and Mach number, that allows the non-dimensional first cell height to be in the range of $0.1<\mathrm{y}^{+}<1$. This step may require more than one grid if there is a wide range of Mach numbers and Reynolds numbers to be analyzed. Third, use the standard SST turbulence model as implemented in USM3D with icompcorr $=0$, ivisc $=8$, $\mathrm{t}$ intsity $=1.2247 \mathrm{e}-5$, and $\mathrm{mut} / \mathrm{mul}=0.009$ in the input file. Finally, use an engine boundary condition computed from a real-gas multispecies and multiphase, chemical reaction simulation in the true nozzle geometry and apply the boundary condition at a truncated nozzle plane. This process can be applied to future rocket designs, such as the Ares V, to determine the extent or lack of plume induced flow separation along the flight path.

\section{Conclusions}

The main objective of the current work was to assess the viability of the USM3D flow solver for predicting PIFS using ideal gas simulations. The secondary objective was to develop a process for calculating PIFS with USM3D. The primary and secondary objectives of the current work were achieved. Ideal gas calculations, using the USM3D CFD code proved to be a viable option for predicting PIFS along the Saturn V.

Saturn V rocket was used in the analysis due to the availability of the flight data and its geometrical similarity to the proposed Ares V vehicle in the post solid rocket booster separation stage. Solutions were computed with ideal gas simulations using the USM3D CFD code at supersonic free stream conditions, zero degree angle of attack, zero degree sideslip angle, and flight Reynolds numbers. Three BC options were investigated to model the F-1 engines firing. The engine $\mathrm{BC}$ was applied to a truncated nozzle face located 2 inches upstream of the nozzle exit.

This study indicated that using the F-1 BC and the SST turbulence model provided the best correlation with flight data for the $\mathrm{M}=6.5$ case with $\mathrm{CECO}$. The F-1 BC was considered the most appropriate method for modeling the engines firing and the SST turbulence model has been shown in other references to do well in predicting cases with separated flow. There was not adequate time to complete the F-1 BC and the SST turbulence model simulations for the $\mathrm{M}=4.4$ case with all five engines firing. In the absence of the F-1 BC and SST solution at $\mathrm{M}=4.4$, the SA turbulence model with the PAB3D BC for the engines firing provided a fair prediction of PIFS for both $\mathrm{M}=4.4$ and $\mathrm{M}=6.5$. 
A grid resolution study was conducted to determine if the solutions were sensitive to grid refinement. The SA turbulence model was used and the PAB3D BC was using for the firing engines. There was a 59 percent increase in cells count from the baseline mesh to the fine mesh and a 33 percent decrease in cell count from the baseline to coarse mesh. For the $\mathrm{M}=4.4$ solution, there was a 2.9 percent change in $\mathrm{L}$ from coarse to medium mesh and no change in L from medium to fine mesh. This result indicated that the baseline mesh was sufficient for preliminary analysis, especially when resource requirements are limited. Coarse mesh solutions were also shown to provide good initial predictions of PIFS with good convergence. For the $\mathrm{M}=6.5$ solution, there was a 1.1 percent change in $\mathrm{L}$ from coarse to medium mesh and a 3.2 percent change in $\mathrm{L}$ from medium to fine mesh. The larger change in $\mathrm{L}$ from the medium to fine mesh was unexpected, but was acceptable when considering that the cell count increased by 59 percent. For initial solutions, the baseline or coarse mesh provided more than accurate assessments of PIFS.

The current paper showed the large variation in calculated PIFS simply due to the profile used for the engine boundary condition for the liquid propellant Saturn V F-1 engines. The USM3D PIFS predictions with the F-1 BC and the SST turbulence model provided good correlation with flight data and a process for calculating PIFS simulations on other launch vehicles has been established. When applying the USM3D PIFS process to other liquid fueled rockets in which flight data is not available, both combinations of boundary condition and turbulence model (the F-1 BC with the SST turbulence model or the PAB3D BC with the SA turbulence model) could be implemented to potentially give a range of expected PIFS distance. Additionally, code-to-code comparisons with the results obtained from the OVERFLOW code are appropriate as a mean to verify the computational results. Direct comparisons for this study were not available to publish herein, but separate OVERFLOW results are available in reference 9 .

\section{References}

1 “NASA's Exploration Systems Architecture Study,” NASA-TM-2005-214062, November 2005.

${ }^{2}$ McElyea, T.: "Project Constellation: Moon, Mars, and Beyond," Apogee Books, 2007.

3 "Constellation Program: America's Fleet of Next-Generation Launch Vehicles, The Ares V Cargo Launch Vehicle," NASA Facts, FS-2009-07-134-MSFC.

${ }^{4}$ Springer, A.: "Experimental Investigation of Plume-Induced Flow Separation on the National Launch System 1.5-stage Launch Vehicle," AIAA 94-0030, January 1994.

${ }^{5}$ Lowery, T. J.: "Effects of Flow Separation on Apollo Saturn V First Stage Aerodynamics," NASA MSFC R-AERO-AD-68-35, June 10, 1968.

${ }^{6}$ O’Connor, E. F.: “Saturn V Launch Vehicle Report," AIAA 66-840, November 29 to December 2, 1966.

${ }^{7}$ Saturn Flight Evaluation Working Group, "Saturn V Launch Vehicle Flight Evaluation Report - AS-506 Apollo 11 Mission," MPR-SAT-FE-69-9, NASA TM-X-62558, September 1969.

${ }^{8}$ Lawrie, A.: "The Saturn V Rocket: A new review of manufacturing, testing, and logistics," AIAA 2006-5031, July 2006.

${ }^{9}$ Kiris, C. C.; Gusman, M.; and Housman, J.: "Best Practices for CFD Simulations of Launch Vehicle Ascent with Plumes," $49^{\text {th }}$ AIAA Aerospace Sciences Meeting, American Institute of Aeronautics and Astronautics, Reston, VA, January 2011.

${ }^{10}$ Parikh, P.; Engelund, W.; Armand, S.; and Bittner, R.: "Evaluation of a CFD Method for Aerodynamic Database Development using the Hyper-X Stack Configuration," AIAA 2004-5385, August 2004.

${ }^{11}$ Pao, S. P.; Vatsa, V. N.; Abdol-Hamid, K. S.; Pirzadeh, S.; Samareh, J. A.; Klopfer, G. H., Taft, J. R., and Parlette, E. B.: "Best Practice for Ascent Aerodynamics Analysis for the Ares I Configurations," Special Session at 55 ${ }^{\text {th }}$ JANNAF Propulsion Meeting in Boston, MA, May 12-16, 2008.

${ }^{12}$ Kiris, C. C., Deere, K. A.; Housman, J., Elmiligui, A., and Gusman, M.: "Best Practices for Aero-Database CFD Simulations of Ares V Ascent Aerodynamics," 49 ${ }^{\text {th }}$ AIAA Aerospace Sciences Meeting, American Institute of Aeronautics and Astronautics, Reston, VA, January 2011 (submitted for publication).

${ }^{13}$ Frink, N. T.; Pirzadeh, S. Z.; Parikh, P. C.; Pandya, M. J.; and Bhat, M. K.: "The NASA Tetrahedral Unstructured Software System," The Aeronautical Journal, Vol. 104, No. 1040, pp. 491-499, October 2000.

${ }^{14}$ Pao, S. P.: "USMC6-TetrUSS Grid and Solution Cutter: A Brief Users' Guide," Version 4, NASA LaRC, October 2008.

${ }^{15}$ Samareh, J.: "GridTool, A Surface Modeling and Grid Generation Tool," Proceedings of the Workshop on Surface Modeling, Grid Generation, and Related Issues in CFD Solutions, NASA CP-3291, May 9-11, 1995.

${ }^{16}$ Pirzadeh, S.: "Unstructured Viscous Grid Generation by Advancing-Layers Method," AIAA Journal, Vol. 32, No. 8, pp. 17351737, August 1994.

${ }^{17}$ Pirzadeh, S.: "Structured Background Grids for Generation of Unstructured Grids by Advancing Front Method," AIAA Journal, Vol. 31, No. 2, pp. 257-265, February 1993.

${ }^{18}$ Pandya, M. J.; Abdol-Hamid, K. S.; and Frink, N. T.: "Enhancement of USM3D Unstructured Flow Solver for High-Speed High-Temperature Shear Flows," AIAA 2009-1329, January 2009.

19 Abdol-Hamid, K. S., Frink, N. T., Deere, K. A., and Pandya, M. J.: "Propulsion Simulations Using Advanced Turbulence Models with the Unstructured-Grid CFD Tool, TetrUSS," AIAA 2004-0714, January 2004.

${ }^{20}$ Abdol-Hamid, K. S.; Pao, S. P.; Hunter, C. A.; Deere, K. A.; Massey, S. J.; and Elmiligui, A.: "PAB3D, Its History in the Use of Turbulence Models in the Simulation of Jet and Nozzle Flows," AIAA 2006-489, January 2006. 
Table 1. Computational Matrix for Saturn V, $\alpha=0^{\circ}, \beta=0^{\circ}$

\begin{tabular}{|c|c|c|c|c|c|c|c|}
\hline $\mathrm{M}_{\infty}$ & Engines Firing & Time, $\mathrm{s}$ & Altitude, $\mathrm{km}$ & $\mathrm{P}_{\infty}, \mathrm{Pa}$ & $\mathrm{T}_{\infty},{ }^{\circ} \mathrm{R}$ & $\mathrm{Re}_{\mathrm{D}}$ & $\mathrm{ReUE}, \mathrm{Millions}$ \\
\hline 1.5 & All 5 & 80 & 15 & 12,111 & 390.6 & $61,522,000$ & 0.15536 \\
\hline 2.7 & All 5 & 100 & 20 & 2,550 & 397.8 & $22,623,000$ & 0.05713 \\
\hline 4.4 & All 5 & 126 & 40 & 151 & 475.2 & $1,697,000$ & 0.00429 \\
\hline 6.5 & CECO & 150 & 60 & 22 & 444.6 & 406,000 & 0.00102 \\
\hline
\end{tabular}

Table 2. First cell height used and the corresponding $\mathrm{y}^{+}$for various Mach numbers

\begin{tabular}{|c|c|c|c|}
\hline $\mathrm{M}_{\infty}$ & Cell Count, Millions & delta1 & $\mathrm{y}^{+}$ \\
\hline 1.5 & 45.5 & 0.002 & 1 \\
\hline 2.7 & 45.5 & 0.002 & 0.2 \\
\hline 4.4 & 40.2 & 0.08 & 0.5 \\
\hline 6.5 & 40.2 & 0.08 & 0.2 \\
\hline
\end{tabular}

Table 3. Cell count for various mesh densities

\begin{tabular}{|c|c|c|c|}
\hline Case & Cell Count, Millions & delta1 & Mesh Density \\
\hline Low $M_{\infty}$ & 45.5 & 0.002 & Medium \\
\hline Low $M_{\infty}$ & 71.8 & 0.002 & Fine \\
\hline High $M_{\infty}$ & 26.7 & 0.08 & Coarse \\
\hline High $M_{\infty}$ & 40.2 & 0.08 & Medium \\
\hline High $M_{\infty}$ & 63.9 & 0.08 & Fine \\
\hline
\end{tabular}

Table 4. Force and moment calculations for determining convergence, $M_{\infty}=6.5, \alpha=0^{\circ}, \beta=0^{\circ}$, and $\operatorname{Re}_{D}=406,000,4$ engines firing, CECO, PAB3D BC, Medium Mesh

\begin{tabular}{|c|c|c|c|c|c|c|}
\hline & $\mathbf{C}_{\mathbf{A}}$ & $\mathbf{C}_{\mathbf{Y}}$ & $\mathbf{C}_{\mathbf{N}}$ & $\mathbf{C}_{\mathbf{I}}$ & $\mathbf{C}_{\mathbf{m}}$ & $\mathbf{C}_{\mathbf{n}}$ \\
\hline Average & 0.220 & -0.0011 & 0.0020 & 0.0001 & 0.0260 & -0.0169 \\
\hline Standard Deviation & $0.14 \mathrm{E}-4$ & $0.16 \mathrm{E}-5$ & $0.10 \mathrm{E}-6$ & $0.17 \mathrm{E}-6$ & $0.12 \mathrm{E}-5$ & $0.26 \mathrm{E}-4$ \\
\hline$\% \mathrm{OR}$ & 0.02 & -0.35 & -0.08 & 0.00 & 0.10 & -0.36 \\
\hline
\end{tabular}

Table 5. $\quad$ Flight Data PIFS distance L, reference 7

\begin{tabular}{|c|c|c|}
\hline$M_{\infty}$ & L, meters & Engines Firing \\
\hline 1.5 & 0 & 5 \\
\hline 2.7 & $3 \pm 0.3$ & 5 \\
\hline 4.4 & $15 \pm 1.5$ & 5 \\
\hline 6.5 & $33 \pm 3.3$ & 4, CECO \\
\hline
\end{tabular}

Table 6. Effect of boundary condition on USM3D predicted PIFS distance L (meters), fine mesh, SA Turbulence Model

\begin{tabular}{|c|c|c|c|c|}
\hline$M_{\infty}$ & Flight Data & F-1 BC & PAB3D BC & APAV BC \\
\hline 1.5 & 0 & Not Computed & 0 & 0 \\
\hline 2.7 & $3 \pm 0.3$ & Not Computed & 0 & 0 \\
\hline 4.4 & $15 \pm 1.5$ & 11.2 & 17.2 & 4.3 \\
\hline 6.5 & $33 \pm 3.3$ & 22.9 & 28.5 & 4.5 \\
\hline
\end{tabular}


Table 7. Effect of Mesh Density on PIFS distance $L$ (meters). SA Turbulence, delta1=0.08, PAB3D BC

\begin{tabular}{|c|c|c|c|}
\hline & Cell Count, Millions & $\mathrm{M}_{\infty}=4.4$ & $\mathrm{M}_{\infty}=6.5$ \\
\hline CFD Coarse Mesh & 26.7 & 16.7 & 27.3 \\
\hline CFD Medium Mesh & 40.2 & 17.2 & 27.6 \\
\hline CFD Fine Mesh & 63.9 & 17.2 & 28.5 \\
\hline FLIGHT DATA & NA & $15 \pm 1.5$ & $33 \pm 3.3$ \\
\hline
\end{tabular}

Table 8. Effect of turbulence model on PIFS distance $L$ (meters) at different mesh densities, F-1 BC, $M_{\infty}=6.5, \alpha=0^{\circ}, \beta=0^{\circ}, \operatorname{Re}_{D}=406,000$. Flight data PIFS $L=33 \pm 3.3$ meters.

\begin{tabular}{|c|c|c|c|}
\hline Turbulence Model & Coarse Mesh & Medium Mesh & Percent Increase in L with Increase in Cell Count \\
\hline SA & 21.5 & 21.7 & 0.93 \\
\hline SST & 34.8 & 35.1 & 0.86 \\
\hline
\end{tabular}

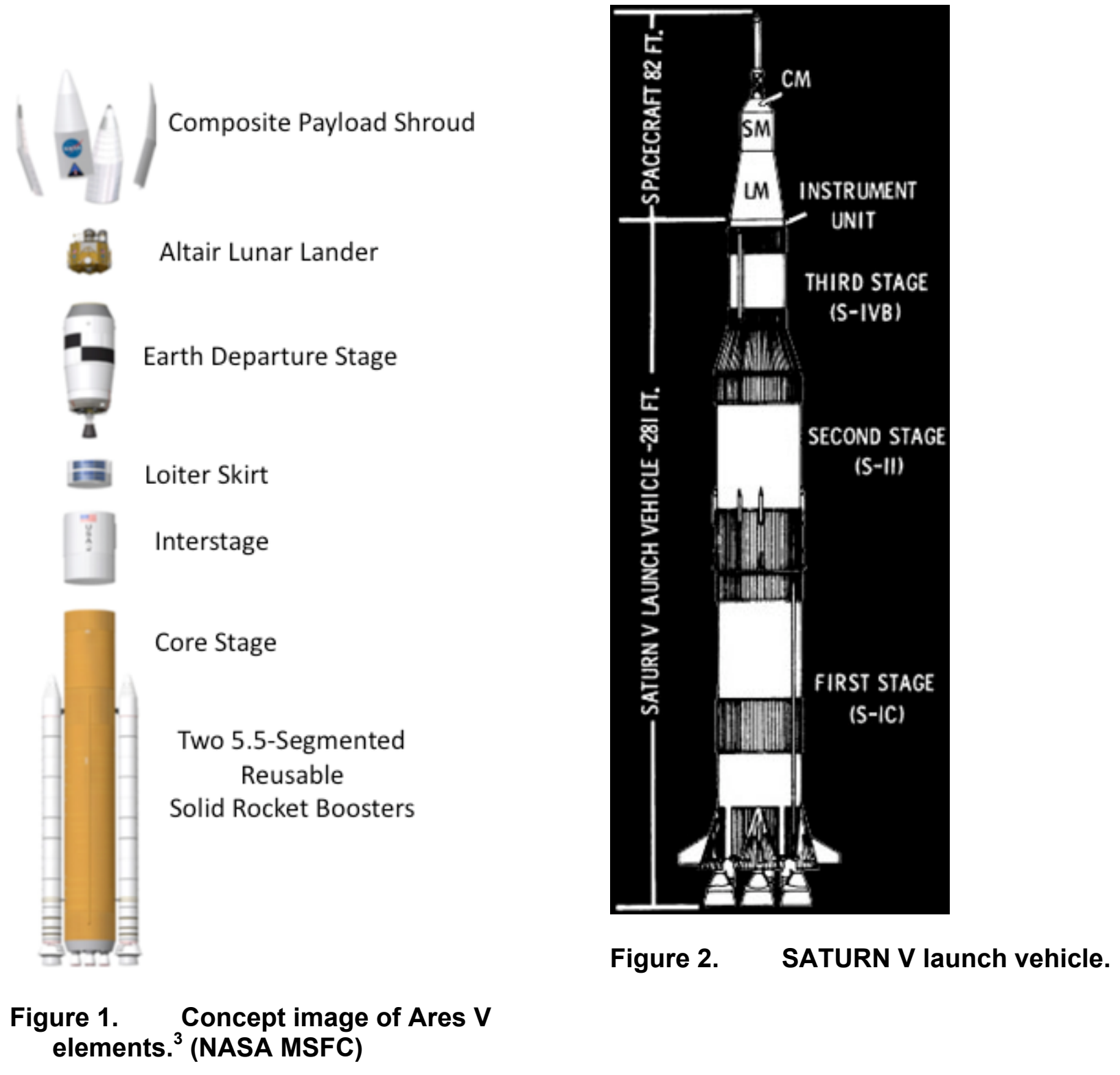


Saturn Flight Evaluation Working group

Saturn V Launch Vehicle Flight Evaluation Report

AS-506 Apollo 11 Mission

TM-X-62558, Sept. 1969
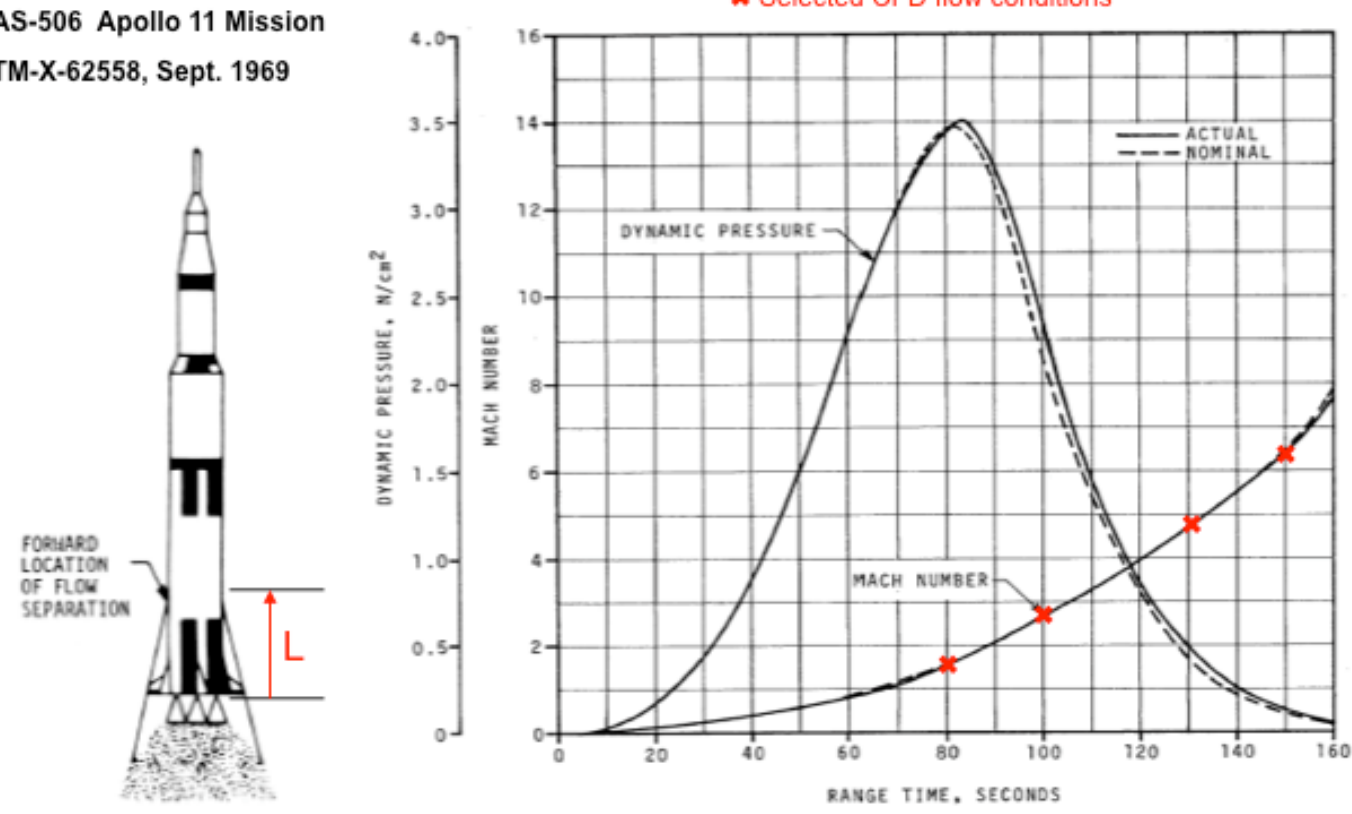

Figure 4-4. Dynanic Pressure and Mach Number Comparisons

(a) Mach number as a function of range time.

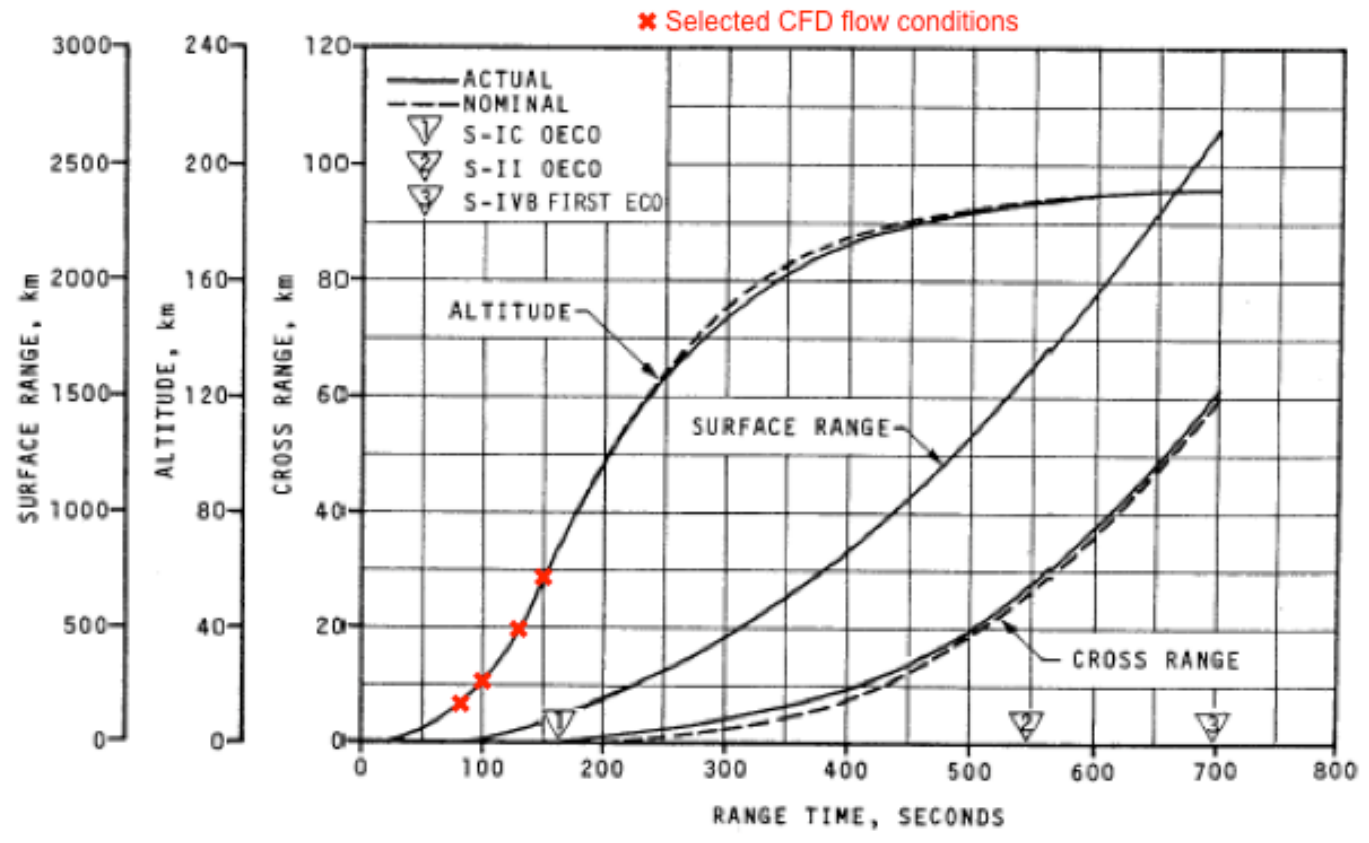

Figure 4-1. Ascent Trajectory Position Comparison

(b) Altitude as a function of range time.

Figure 3. Saturn $\mathbf{V}$ data from reference 7 . 


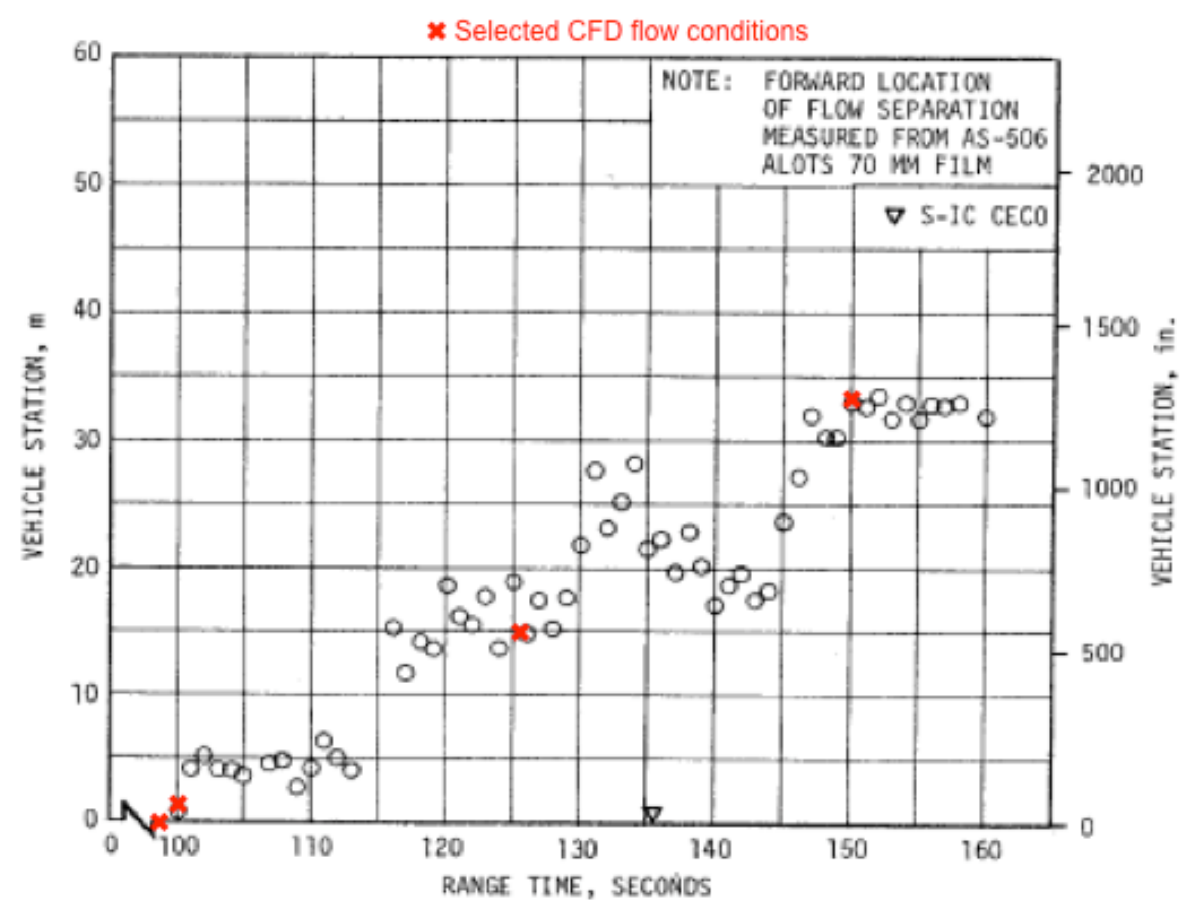

Figure 17-7. Forward Location of Separated Flow

(c) PIFS distance as a function of range time.

Figure 3. Concluded.

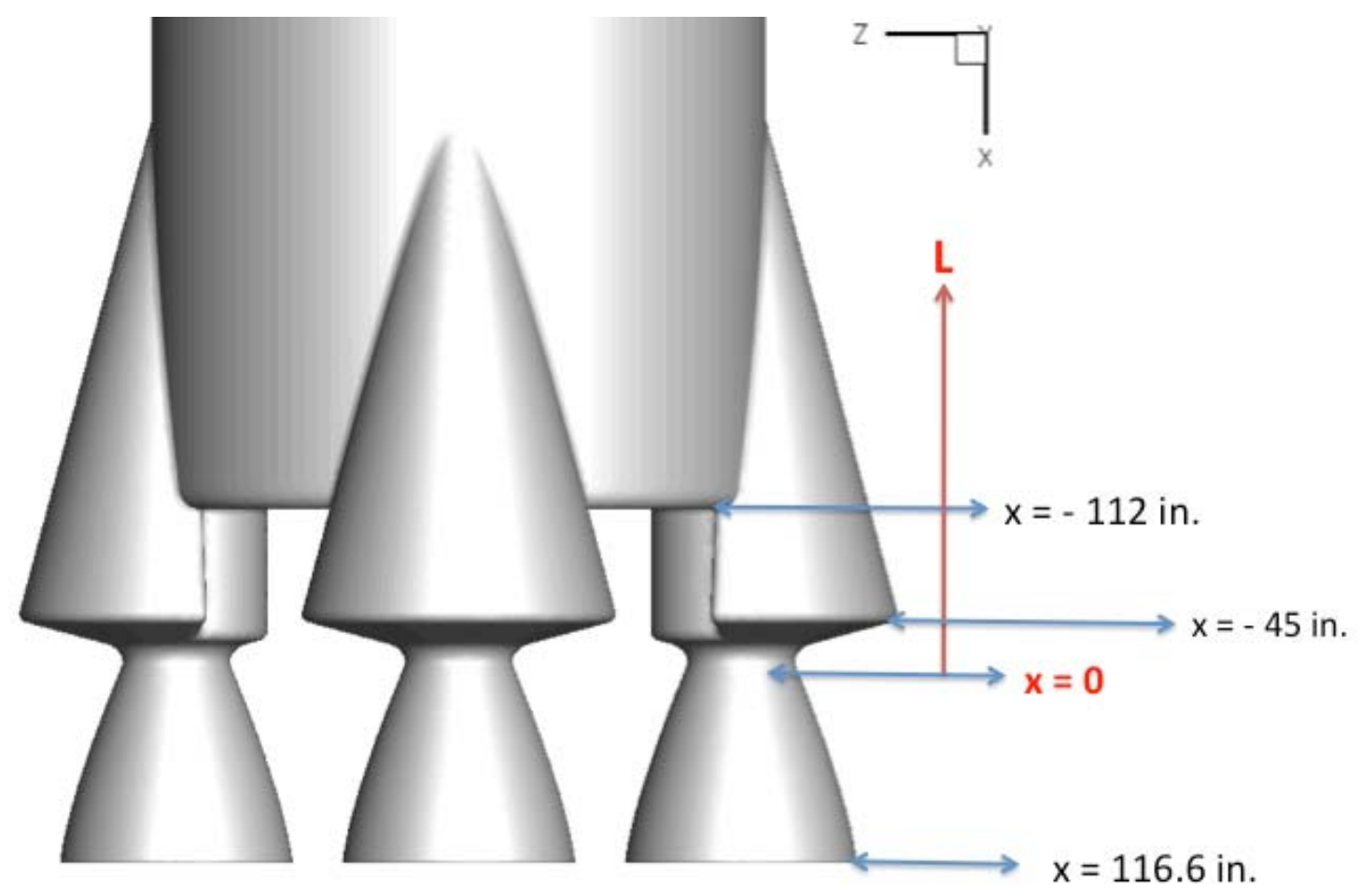

Figure 4. Saturn V reference location for calculating PIFS distance $L$. 

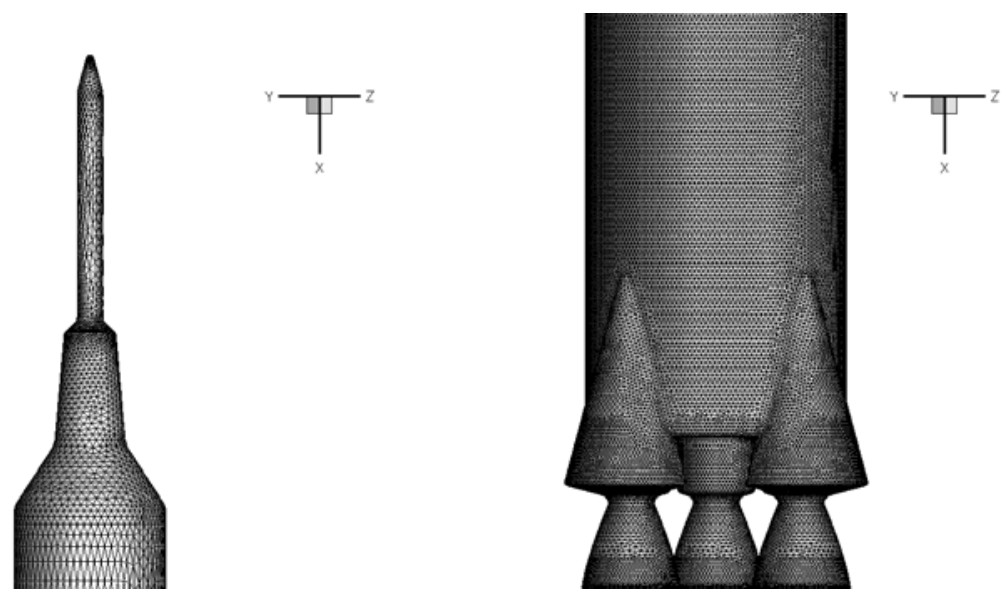

a) Surface mesh of grid with $\mathbf{2 6 . 7}$ million cells.
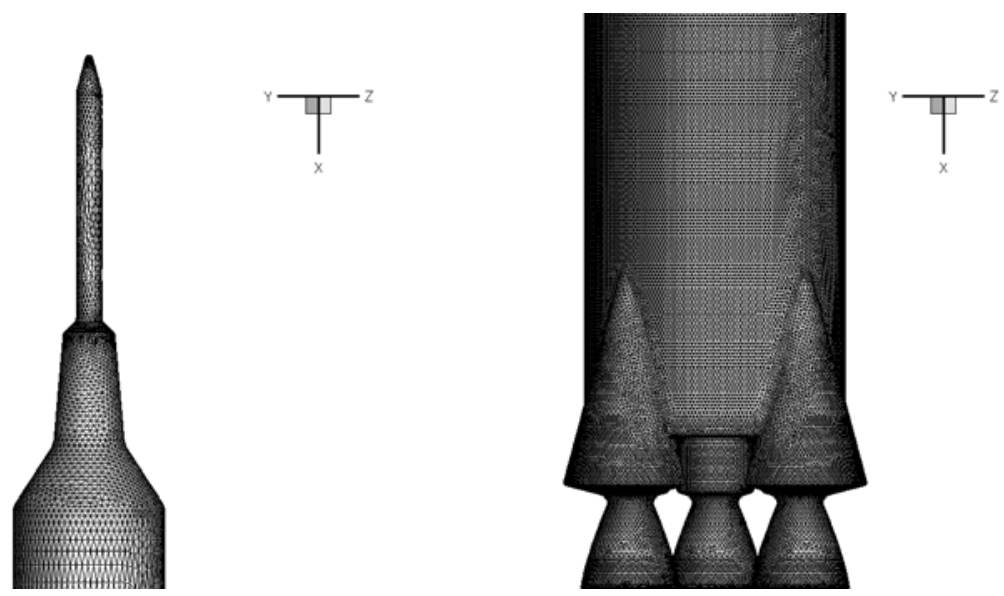

b) Surface mesh of grid with $\mathbf{4 0 . 2}$ million cells.
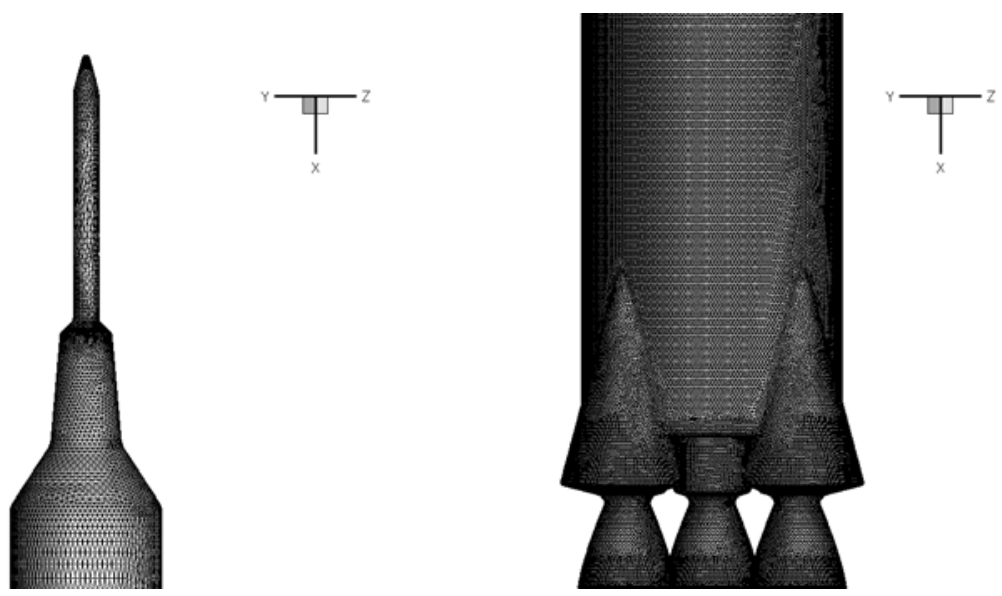

c) Surface mesh of grid with 63.9 million cells.

Figure 5. Comparison of Saturn V surface meshes for various grid densities. 


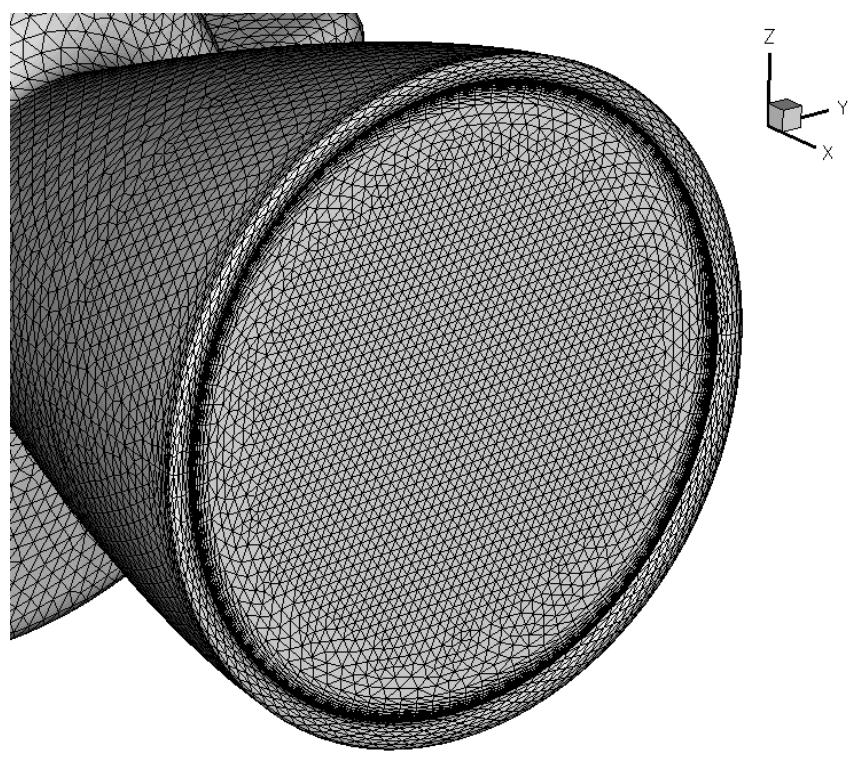

Figure 6. Truncated nozzle, with the boundary condition plane located 2 inches upstream of the F-1 nozzle exit.

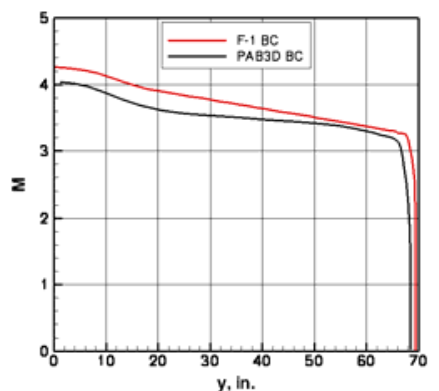

a) Mach number

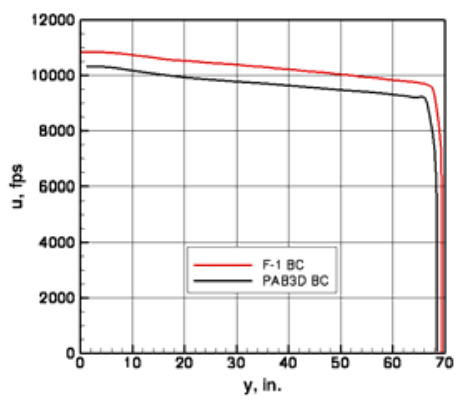

b) Axial Velocity

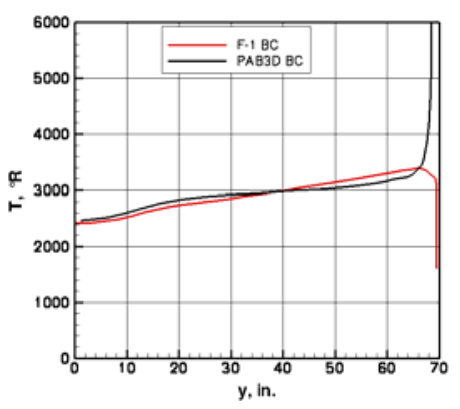

c) Temperature

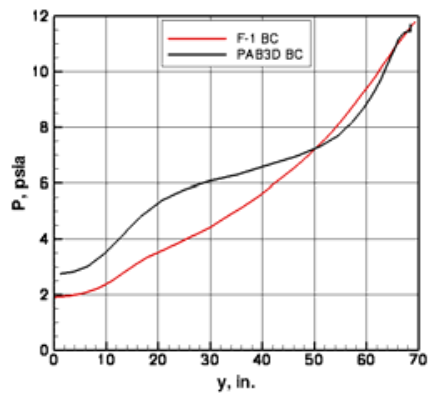

d) Pressure

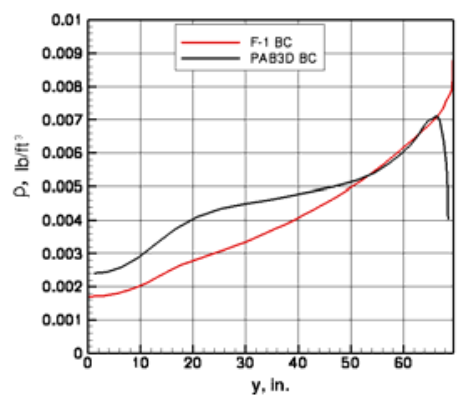

e) Density

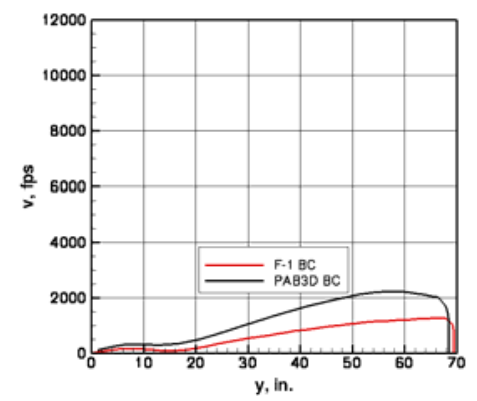

f) Radial Velocity

Figure 7. Comparison of boundary conditions: F-1 BC from true nozzle and PAB3D $B C$ from a modified expansion ratio nozzle. 


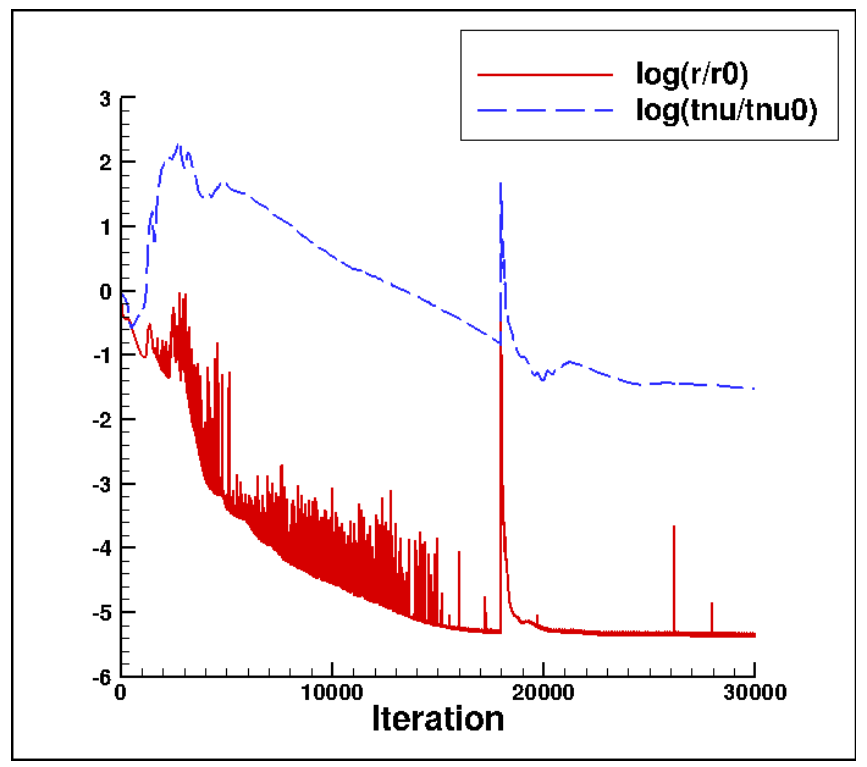

a) residual history
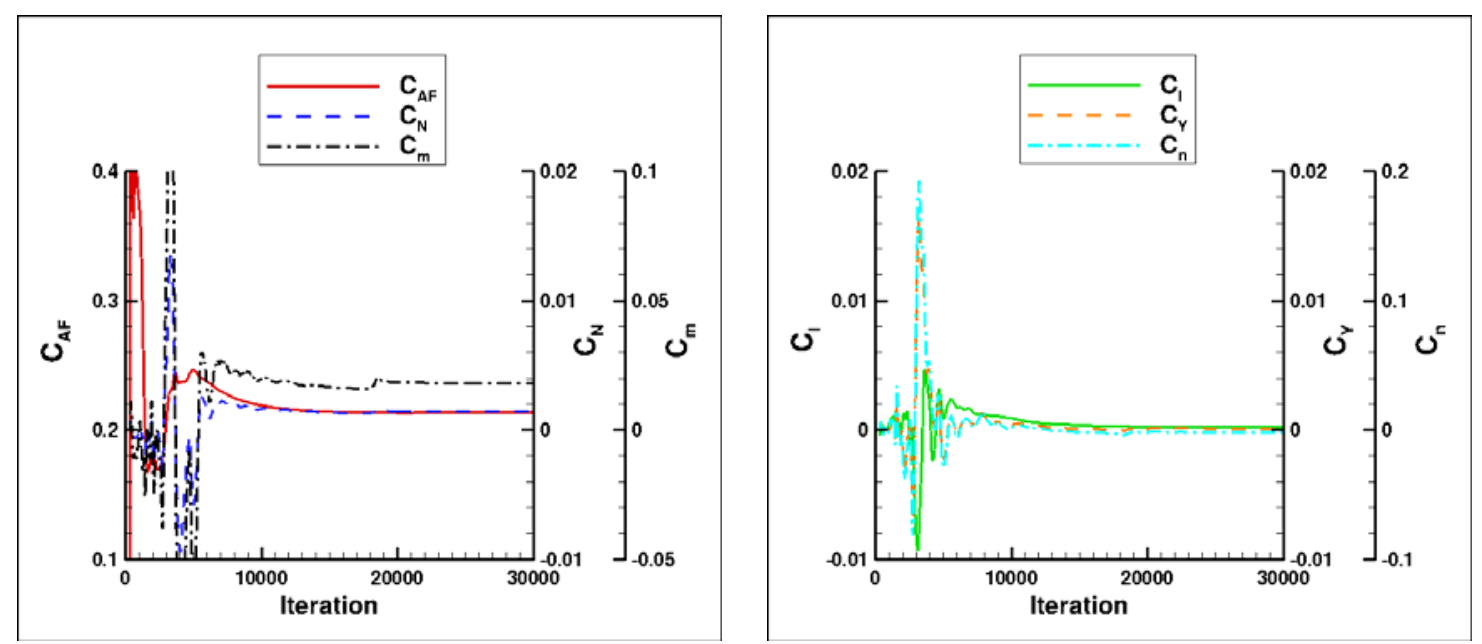

b) coefficient history

Figure 8. Typical convergence plots. The solution shown here is for the Saturn V rocket at $M_{\infty}=6.5, \alpha=0^{\circ}, \beta=0^{\circ}$, and $\operatorname{Re}_{D}=406,000$, using USM3D with the SA turbulence model and a medium mesh. Case for CECO with four engines firing and modeled with the F-1 BC. 


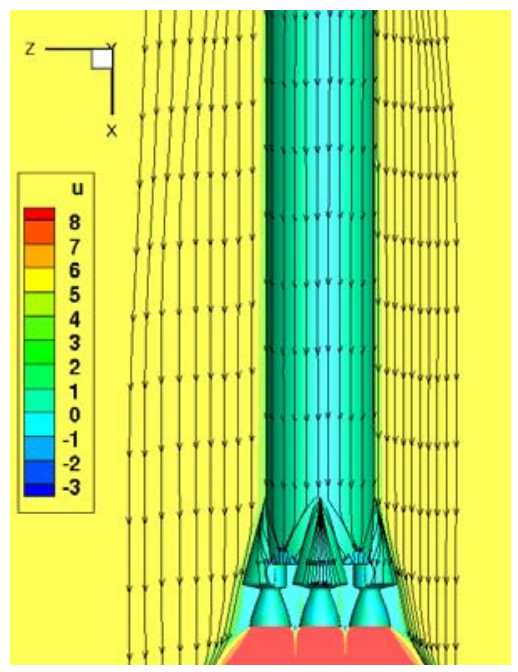

a) APAV BC, L $=4.3 \mathrm{~m}$

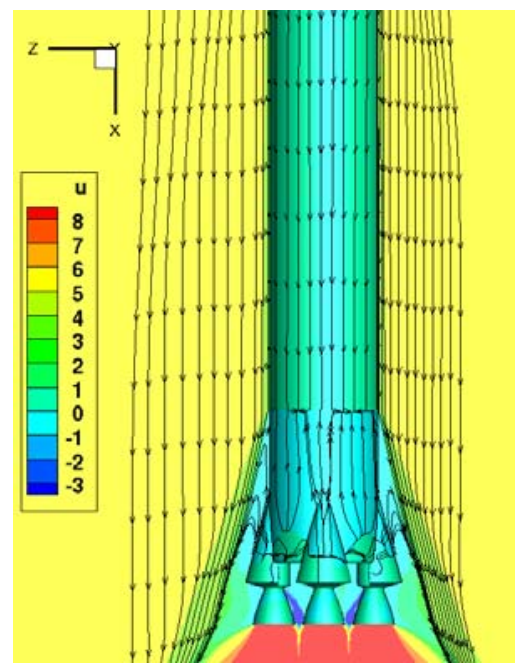

b) PAB3D BC, L = $17.2 \mathrm{~m}$

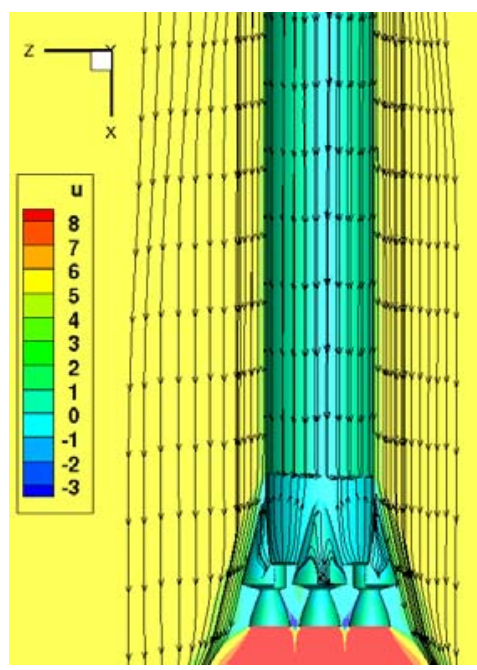

c) $F-1 B C, L=11.2 \mathrm{~m}$

Figure 9. Effects of engine boundary condition on PIFS for the non-dimensional off surface velocity contours and velocity-based surface streamtraces at $M_{\infty}=4.4, \alpha=0^{\circ}$, $\beta=0^{\circ}$, and $\operatorname{Re}_{D}=1,697,000$. Fine mesh grid and SA turbulence model. Flight measured PIFS distance $L=15 \pm 1.5$ meters.

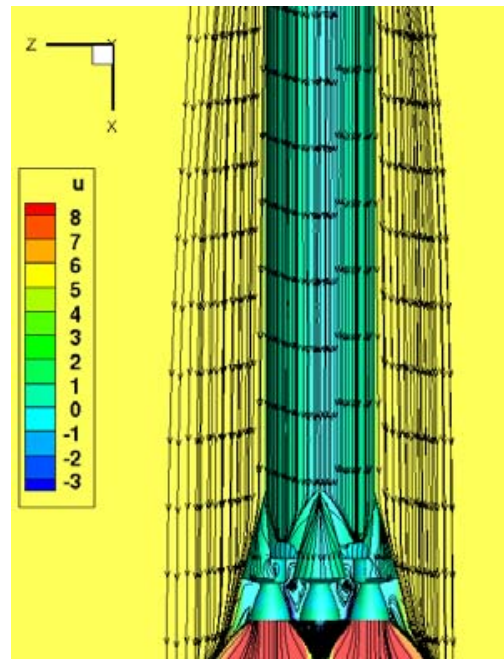

a) APAV BC, $L=4.5 \mathrm{~m}$

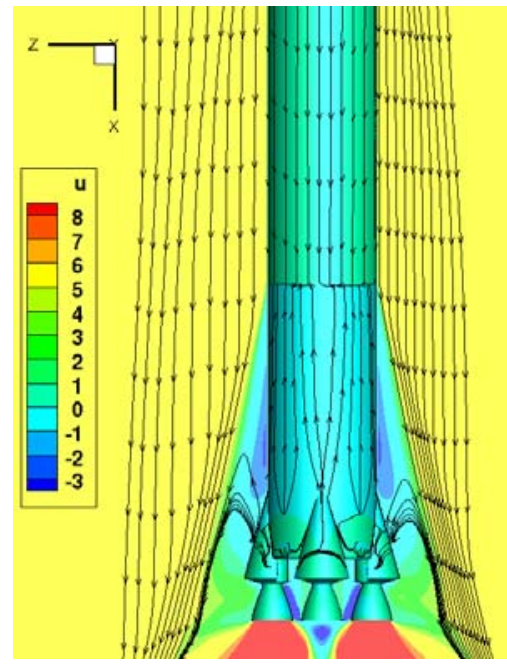

b) PAB3D BC, L $=28.5 \mathrm{~m}$

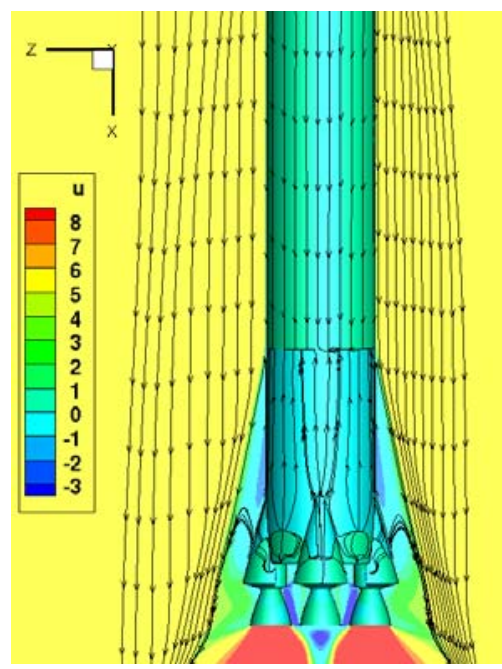

c) F-1 BC, L $=22.8 \mathrm{~m}$

Figure 10. Effects of engine boundary condition on PIFS for the non-dimensional off surface velocity contours and velocity-based surface streamtraces at $M_{\infty}=6.5, \alpha=0^{\circ}$, $\beta=0^{\circ}$, and $\operatorname{Re}_{D}=406,000$ with CECO. Fine mesh grid and SA turbulence model. Flight measured PIFS distance $L=33 \pm 3.3$ meters. 


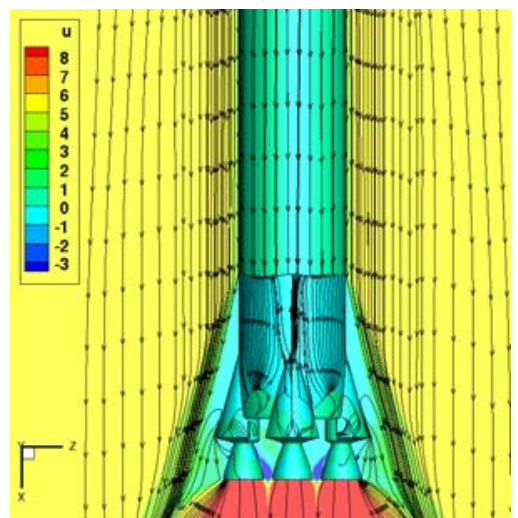

a) Coarse Mesh, L=16.7 m

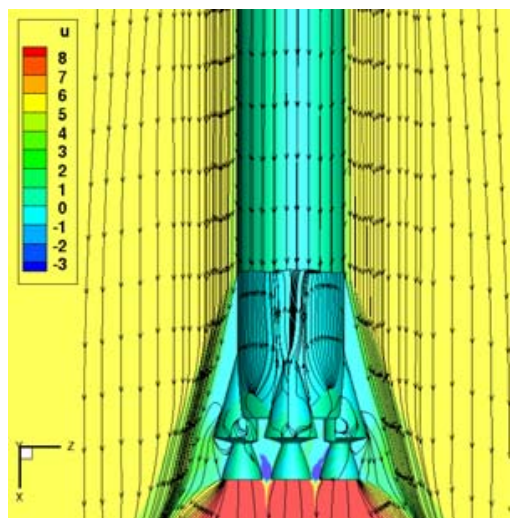

b) Medium Mesh, L=17.2 m

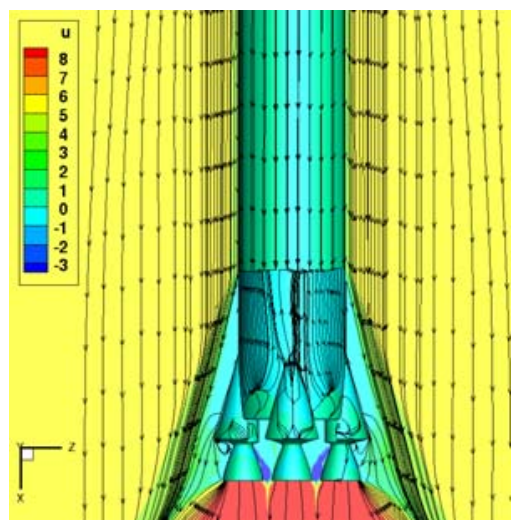

c) Fine Mesh, L=17.2 m

Figure 11. Effects of grid refinement on PIFS for the non-dimensional off surface velocity contours and velocity-based surface streamtraces at $M_{\infty}=4.4, \alpha=0^{\circ}, \beta=0^{\circ}$, and $\operatorname{Re}_{\mathrm{D}}=1,697,000$. SA turbulence model and PAB3D BC for the engines firing. Flight measured PIFS distance $L=15 \pm 1.5$ meters

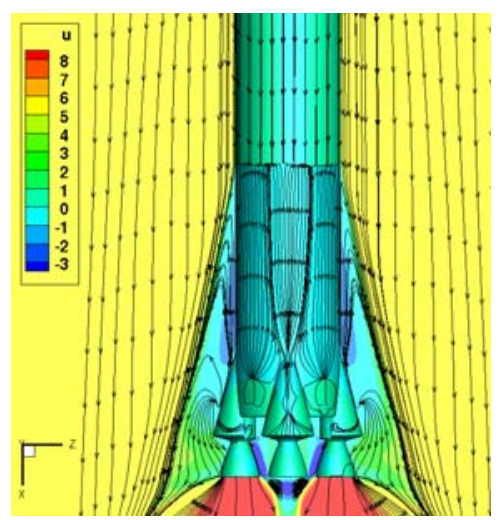

a)Coarse Mesh, L=27.3 m

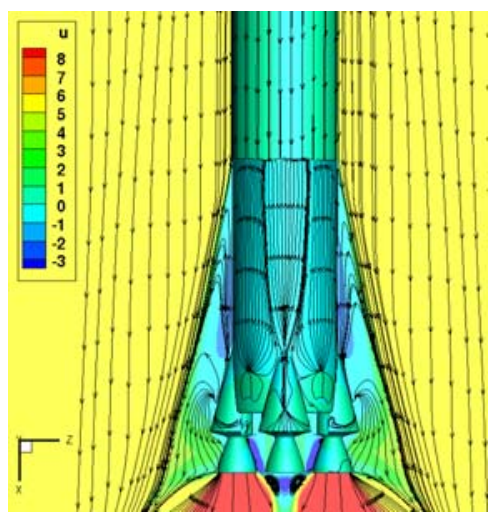

b) Medium Mesh, L=27.5 m

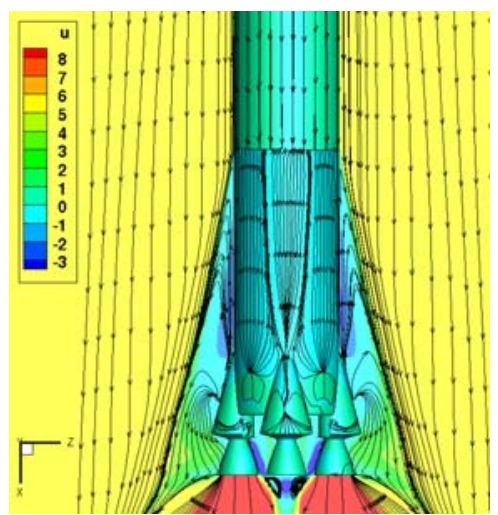

c) Fine Mesh, L=28.5 m

Figure 12. Effects of grid refinement on PIFS for the non-dimensional off surface velocity contours and velocity-based surface streamtraces at $M_{\infty}=6.5, \alpha=0^{\circ}, \beta=0^{\circ}$, and $\operatorname{Re}_{\mathrm{D}}=406,000$ with CECO. SA turbulence model and PAB3D BC for the engines firing. Flight measured PIFS distance $L=33 \pm 3.3$ meters. 


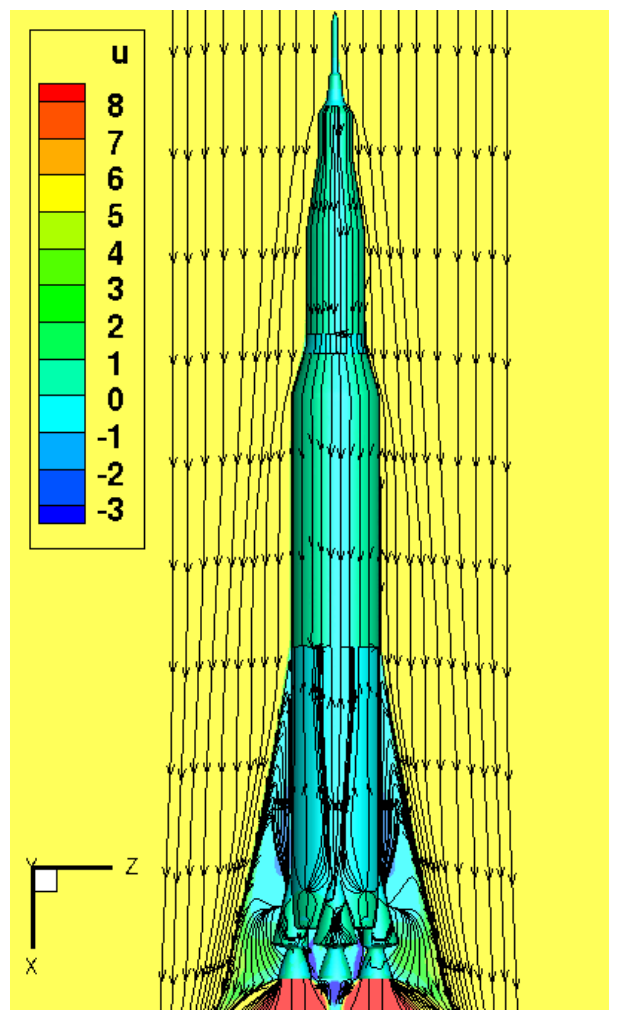

a) Full geometry

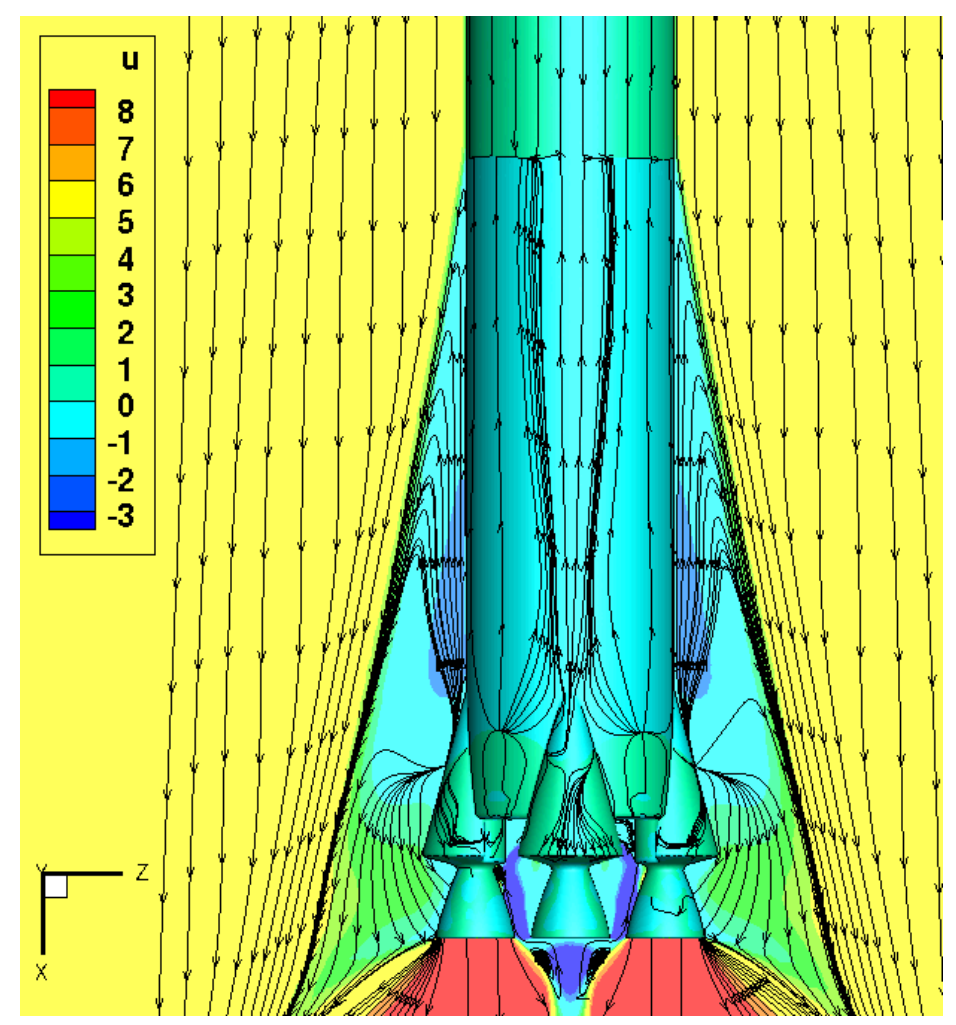

b) View of F-1 nozzles and PIFS region, $\mathrm{L}=35.1 \mathrm{~m}$.

Figure 13. Non-dimensional off surface velocity contours and velocity-based surface streamtraces at $M_{\infty}=6.5, \alpha=0^{\circ}, \beta=0^{\circ}$, and $\operatorname{Re}_{D}=406,000$ with CECO. SST turbulence model and F-1 BC for the 4 firing engines. Flight measured PIFS distance $L=33 \pm 3.3$ meters. 